\title{
IS AGE ASSOCIATED WITH SELF-RATED HEALTH AMONG OLDER PEOPLE IN SPAIN?
}

\section{Pedro Girón}

Department of Statistics and Operations Research III, Statistics School, Universidad Complutense de Madrid, Madrid, Spain

\section{SUMMARY}

Objective: To examine the association of age and other factors with Self-rated Health (SRH) in the population aged 65 years or more in the context of action for health promotion in older adults.

Material and Methods: The data used come from the household and adults questionnaires of the National Health Survey of Spain for 2006. SRH was categorized as positive (very positive or positive) and negative (fair, poor or very poor). Odds ratios for positive SRH compared to negative $\mathrm{SRH}$ were calculated using logistic regression models for complex samples. The determinants of the Positive SRH were obtained for the elderly population.

Results: Among the population aged 65 years and older $39.7 \%$ report positive SRH. In this age group, those of 83 or more years have a better SRH. Other factors specific to this age group that improve the SRH are living alone, not having any functional dependence and high monthly family income.

Conclusions: The association between several factors (particularly age) and positive SHR in people aged 65 and older differs from the one found in the rest of the population. Understanding the factors positively associated with the positive SRH in this population is of great importance for the design of specific programmes aimed at improving the health of older people.

Key words: elderly population, self-rated health, healthy habits, logistic models, complex samples

Address for correspondence: Pedro Girón, Department of Statistics and Operations Research III, Statistics School, Universidad Complutense de Madrid, Avda. Pta Hierro s/n, 28040 Madrid, Spain. E-mail: pgiron@estad.ucm.es

\section{INTRODUCTION}

Self-rated Health (SRH) has been a widely used health indicator in health inequalities research in developed countries, particularly in the elderly population. Over the last twenty years in Spain and other similar countries research has consisted of describing the assessment of SHR, and its association with various health indicators (morbidity, disability, healthy habits, and use of health services) and sociodemographic characteristics (sex, age, social class, educational level, region of residence) (1-7). These studies found most of these factors being related with SHR; in particular, they conclude that health worsens with age and individuals from 65 or more years old do not differ in SRH from older cohorts. Such studies deployed prior to 2006 editions of the National Health Survey (NHS) of Spain. There is also evidence from data-sets different from NHS (8-10), where an association between age and the SHR is observed consistently with the abovementioned studies. Moreover, recent studies with NHS 2006 showed differences by age group for adults (11), particularly SRH worsens with age until the age of 49 , while from 50 years old onwards people report better health than the younger.

To the best of our knowledge there are no studies neither testing whether this relationship is monotonic over age, nor assessing the influence of various factors, such as lifestyle, morbidity and disability on SRH in the population aged 65 years or more. Adopting this approach in the analysis of the SRH is necessary because of at least two reasons: firstly, the rise in chronic diseases and increased life expectancy in developed countries have created health inequalities between different age groups and particularly in elderly population; secondly, because SRH is a multidimensional indicator associated not only with health indicators such as mortality and morbidity but also with sociodemographic, disability, lifestyle and health services (12). It is possible to detect how these factors affect health in this age group. Therefore, we intend to analyze the relation between age and other factors with SRH in the population aged 65 years or more in order to understand the inequities in health for better guidance on specific public health programmes.

\section{MATERIALS AND METHODS}

\section{Sampling}

The NHS of Spain is a biennial survey conducted by the Ministry of Health and Consumer Affairs since 1987 and it has evolved methodologically and conceptually over the years. The NHS 2006 was adapted to the requirements of the European Health Survey project. This survey adds new domains of health, such as mental and social health. The fieldwork of the survey was conducted by the National Statistics Institute from June 2006 to June 2007. The survey consists of three questionnaires: one for the household, 
one for adults and a third one for children. The data collection method is a structural personal interview of individuals older than 16 years. The sample design is a three-stage stratified sampling, where the first-stage units are census tracts (grouped into seven strata according to the size of the municipality in the census tract), the second stage units are family households and third stage units consist of a selected adult in every household. The census tracts are selected with probability proportional to size in each stratum, households are selected with equal probability using systematic sampling and adults in each household have an equal probability of being selected. The NHS 2006 is performed on the 18 administrative regions (comunidades autónomas) in Spain. The adults' questionnaire provides information on reproductive work, health and chronic diseases, mental health, restrictions to activity, use of medications, limitations, personal and emotional support, family function, use of health services, lifestyle and sociodemographic characteristics of the selected person and household. A more detailed description of the NHS 2006, its sample design and questionnaires can be found in References No. 13, 14.

The sample consisted of 31,300 households distributed in 2,236 census tracts, 29,478 of which collected information from 7,835 people aged 65 years or more (mean \pm SD) $75 \pm 6.7$ years, $57.3 \%$ of which are women.

\section{Outcome Measures}

Information on the dependent variable, SRH, was obtained through the following question: "In the last twelve months, would you say your health has been very good, good, fair, bad, very bad?". The dependent variable reflects Positive Self-rated Health (PSRH) and takes value "1" if the answer was "good" or "very good" and "0" if the answer was "regular", "bad" or "very bad".

\section{Explanatory Variables}

The explanatory variables correspond to four different domains: sociodemographic variables, variables related to disease and disability, lifestyles, and use of health services.

\section{Sociodemographic Variables}

The main sociodemographic variables are gender, age (categorized into 2 age groups), social class (defined according to the Spanish Society of Epidemiology) (15), monthly family income (in 5 categories), educational level (in 3 categories), living alone, presence of people needing care in the household, whether the person has devoted time to housework duties, family function and region of residence (included as a control variable).

\section{Disease and Disability Variables}

The first variable of this group, chronic disease problems or limitations in the past 12 months, has been constructed from answers to whether respondents have ever or in the past 12 months suffered from any disease of 27 listed conditions. Additionally, those who reported at least one disease in the last 12 months were asked whether the disease limited their usual activities, which allows us to distinguish between those with disease and limitation, those with disease and no limitation and those with no disease. Other variables included are the state of mental health in recent weeks (12-item General Health Questionnaire, GHQ-12), whether the interviewee has had any accident during the past 12 months, whether he/she experienced any restrictions when conducting normal activities in the last two weeks, whether he/ she had constraints to perform daily life activities in the last six months, whether he/she has currently hearing or vision problems and whether he/she had any functional dependence (personal care or housework or mobility).

\section{Lifestyle Variables}

Interviewees reported whether they had smoked in the past 8 weeks and how often (if any) they had drank alcohol in the past 12 months; we distinguish between: none, occasionally (once per month or less) and habitually (with daily or weekly periodicity). Other lifestyle variables refer to resting enough sleeping hours, physical activity performed as the main activity, doing physical activity in leisure time, and body mass index. The latter was measured with the Quetelet index for 18 or more year-olds.

\section{Use of Health Services Variables}

Participants reported time since the last medical consultation, whether they had been hospitalized in the past 12 months, whether they had used emergency services in the past 12 months, time since the last visit to the dentist and number of drugs consumed in the last two weeks. The latter variable is referred to 22 pharmaceutical subgroups and comprises both physician-prescribed and self-medication. We distinguish between the consumption of none, one, two and three or more drugs.

\section{Statistical Analysis}

Descriptive analysis was performed for the dependent and explanatory variables in the sample. Given the complex sample design, estimation took each observation sampling weight into account and standard errors were obtained by the Taylor linearization method in order to get more precise estimates $(16,17)$.

Before building the Multivariate Logistic Regression model (MLR) a previous univariate association analysis was performed between SRH and each of the explanatory variables using the adjusted Wald statistic, p-value associated with the statistics and the odds ratio (OR). All those variables showing association with PSRH below $\mathrm{p}=0.25$ were potential covariates for the multivariable model. The MLR was constructed controlling for confounding between the explanatory variables according to the criterion of Maldonado and Greenland $(18,19)$. Once the multivariate model was adjusted, the Hosmer-Lemeshow test for complex sample designs (20) was used to test whether it was well-specified.

Results were presented as OR, p-values and 95\% confidence intervals $(95 \% \mathrm{CI})$. Negative health was used a reference category. STATA 9 software was deployed for the statistical analysis.

\section{RESULTS}

Overall, $39.7 \%$ of elderly people report positive SRH. In univariate logistic regression, all variables show an association with SRH, except living alone and time since the last query to the dentist (Tables 1-3).

Table 4 shows the results of the MLR for the population aged 65 years or more. In this population PSRH does not decrease 
Table 1. Univariate analysis of SRH for the population aged 65 years or more controlling for region of residence: Sociodemographic variables.

\begin{tabular}{|l|c|c|c|}
\hline Variables & $(\%)$ & SRH (\%) & OR \\
\hline Positive SRH & & 39.7 & \\
\hline Age* $^{*}$ & 86.4 & 40.2 & 1.158 \\
\hline 65 to 82 years & 13.6 & 36.7 & 1 \\
\hline Over 82 years & 42.7 & 48.5 & 1.901 \\
\hline Sex* & 57.3 & 33.1 & 1 \\
\hline Man &
\end{tabular}

\begin{tabular}{|l|c|c|c|}
\hline Social class* & \multicolumn{3}{|l}{} \\
\hline Class I/Class II & 12.0 & 57.4 & $2.878^{*}$ \\
\hline Class III & 24.9 & 40.8 & $1.474^{*}$ \\
\hline Class IV & 41.1 & 38.5 & $1.338^{*}$ \\
\hline Class V & 22.0 & 31.8 & 1 \\
\hline
\end{tabular}

Monthly family income*

\begin{tabular}{|l|c|c|c|}
\hline Up to $900 €$ & 45.3 & 33.7 & $0.407^{*}$ \\
\hline 901 to $1,200 €$ & 17.9 & 42.8 & $0.599^{*}$ \\
\hline 1,201 to $1,800 €$ & 13.3 & 44.3 & $0.638^{*}$ \\
\hline More than $1,800 €$ & 8.6 & 55.5 & 1 \\
\hline Unknown & 14.8 & 40.5 & $0.546^{*}$ \\
\hline
\end{tabular}

\section{Educational attainment*}

\begin{tabular}{|l|c|c|c|}
\hline Illiterate or no education & 37.1 & 28.8 & $0.214^{*}$ \\
\hline Primary and secondary 1st cycle & 49.7 & 41.8 & $0.381^{*}$ \\
\hline $\begin{array}{l}\text { 2nd cycle secondary } \\
\text { and postsecondary }\end{array}$ & 7.2 & 59.1 & 0.765 \\
\hline University & 6.1 & 65.4 & 1 \\
\hline
\end{tabular}

\section{Living alone}

\begin{tabular}{|l|c|c|c|}
\hline Yes & 18.6 & 38.6 & 0.942 \\
\hline No & 81.4 & 40.0 & 1 \\
\hline
\end{tabular}

There are people who need care in the household*

\begin{tabular}{|l|c|c|c|}
\hline Yes & 26.2 & 28.5 & 0.515 \\
\hline No & 73.8 & 43.6 & 1 \\
\hline
\end{tabular}

The interviewee devotes time to housework duties*

\begin{tabular}{|l|c|c|c|}
\hline Yes, alone & 36.8 & 38.5 & 1.011 \\
\hline Yes, shared & 22.1 & 44.8 & $1.315^{\star}$ \\
\hline No & 41.0 & 38.2 & 1 \\
\hline
\end{tabular}

Family function*

\begin{tabular}{|l|c|c|c|}
\hline Good & 84.2 & 41.1 & 1 \\
\hline Moderate-Severe & 8.2 & 32.0 & $0.674^{*}$ \\
\hline Unknown & 7.6 & 32.1 & $0.677^{*}$ \\
\hline
\end{tabular}

$n=7,835 ;{ }^{*} p<0.05$; values without asterisk are not significant $(p \geq 0.05)$

with age: people over 82 years report a better SRH than people between 65 and 82 years of age.

In addition, other factors associated with PSRH were the higher monthly family income, higher education attainment, living alone, having no chronic illnesses, being in good mental health, having no restrictions when conducting normal activities in the last two
Table 2. Univariate analysis of SRH for the population aged 65 years or more controlling for region of residence: Morbidity and disability.

\begin{tabular}{|l|c|c|c|}
\hline Variables & $(\%)$ & SRH (\%) & OR \\
\hline Chronic disease problem or limitation in the past 12 months* $^{*}$ \\
\hline Disease with limitations & 38.1 & 12.1 & $0.024^{*}$ \\
\hline Disease without limitations & 55.6 & 53.4 & $0.204^{*}$ \\
\hline Without disease \\
\hline Mental health* \\
\hline Good & 6.3 & 84.9 & 1 \\
\hline Not good & 64.3 & 50.5 & 1 \\
\hline Unknown & 26.4 & 14.7 & $0.169^{*}$ \\
\hline Limitation of daily activities in the last 6 months & 36.1 & $0.553^{*}$ \\
\hline Yes & 40.8 & 13.4 & 0.113 \\
\hline No & 59.2 & 57.8 & 1 \\
\hline
\end{tabular}

Restriction of normal activities due to pain or symptoms in the last 2 weeks

\begin{tabular}{|l|c|c|c|}
\hline Yes & 17.9 & 12.1 & 0.163 \\
\hline No & 82.1 & 45.7 & 1 \\
\hline
\end{tabular}

Accident in the past 12 months ${ }^{*}$

\begin{tabular}{|l|c|c|c|}
\hline Yes & 10.5 & 24.8 & 0.467 \\
\hline No & 89.5 & 41.4 & 1 \\
\hline
\end{tabular}

Hearing impaired*

\begin{tabular}{|l|c|c|c|}
\hline No & 73.1 & 42.4 & 1.540 \\
\hline Yes & 26.9 & 32.4 & 1 \\
\hline Visually impaired* \\
\hline No & 87.1 & 41.8 & 2.080 \\
\hline Yes & 12.9 & 25.7 & 1 \\
\hline
\end{tabular}

Any functional dependence*

\begin{tabular}{|l|c|c|c|}
\hline Yes & 48.6 & 22.6 & 0.230 \\
\hline No & 51.4 & 56.0 & 1 \\
\hline
\end{tabular}

$n=7,835 ;{ }^{*} p<0.05$; values without asterisk are not significant $(p \geq 0.05)$

weeks, having no constraints to perform daily life activities in the last six months, having no functional dependence, having physical activity during leisure time, getting enough rest, not having been hospitalized, not having used the emergency services, longer time since last medical consultation and fewer drugs consumed.

\section{DISCUSSION}

The main findings of this study show differences between adults in the elderly population in Spain between those in the age group from 65 to 82 years old and those 83 and older. In particular those from 83 and older are more likely to report better SRH.

Moreover, persons who live alone or have no functional dependence report a higher SRH, which is reflecting that people in a position of autonomy and independence rated their health more highly regardless family support and social agencies.

Finally, the findings of this work indicate that the level of education and monthly family incomes are important predictors 
Table 3. Univariate analysis of $\mathrm{SRH}$ for the population aged 65 years or more controlling for region of residence: Lifestyle and use health services and drug consumption.

\begin{tabular}{|c|c|c|c|}
\hline Variables & $(\%)$ & SRH (\%) & OR \\
\hline \multicolumn{4}{|l|}{ Lifestyle } \\
\hline \multicolumn{4}{|l|}{ Smoking* } \\
\hline Smokers & 8.3 & 71.5 & $1.730^{*}$ \\
\hline Non smoker & 25.7 & 63.5 & $1.413^{*}$ \\
\hline Has never smoked & 66.0 & 64.8 & 1 \\
\hline \multicolumn{4}{|l|}{ Alcohol consumption in past 12 months* } \\
\hline No & 47.6 & 31.9 & $0.705^{*}$ \\
\hline Habitual & 40.4 & 49.0 & $1.445^{*}$ \\
\hline Occasional & 11.9 & 40.0 & 1 \\
\hline \multicolumn{4}{|l|}{ Sleep enough hours* } \\
\hline Yes & 81.6 & 44.5 & 3.407 \\
\hline No & 18.4 & 19.1 & 1 \\
\hline \multicolumn{4}{|l|}{ Physical activity during leisure time* } \\
\hline Yes & 62.7 & 47.2 & 2.352 \\
\hline No & 37.3 & 27.5 & 1 \\
\hline \multicolumn{4}{|l|}{ Physical activity in the main activity* } \\
\hline Sitting most of the day & 45.7 & 31.6 & $0.371^{*}$ \\
\hline $\begin{array}{l}\text { Standing most of the day without } \\
\text { making a major effort }\end{array}$ & 47.7 & 45.3 & $0.664^{*}$ \\
\hline Frequent travel or making great efforts & 6.6 & 55.5 & 1 \\
\hline \multicolumn{4}{|l|}{ Body mass index* } \\
\hline Normal weight/Underweight & 23.7 & 44.1 & 1 \\
\hline Overweight & 37.2 & 43.3 & 0.968 \\
\hline Obesity & 18.9 & 36.6 & $0.733^{*}$ \\
\hline Unknown & 20.2 & 30.8 & $0.564^{*}$ \\
\hline \multicolumn{4}{|c|}{ Use of the health services and drug consumption } \\
\hline \multicolumn{4}{|l|}{ Time since last medical consultation* } \\
\hline 4 weeks or less & 59.1 & 31.6 & $0.131^{*}$ \\
\hline More than 4 weeks and less than 1 year & 34.6 & 46.6 & $0.247^{*}$ \\
\hline 1 year or more & 6.3 & 77.9 & 1 \\
\hline \multicolumn{4}{|l|}{ Hospitalization in the past 12 months* } \\
\hline Yes & 21.6 & 19.9 & 0.301 \\
\hline No & 78.4 & 45.2 & 1 \\
\hline \multicolumn{4}{|c|}{ Use of the emergency services in the past 12 months* } \\
\hline Yes & 29.7 & 20.6 & 0.283 \\
\hline No & 70.3 & 47.8 & 1 \\
\hline \multicolumn{4}{|l|}{ Time since last visit to the dentist } \\
\hline 3 months or less & 13.1 & 40.4 & 1.059 \\
\hline More than 3 and less than 12 months & 11.7 & 43.5 & 1.202 \\
\hline 1 year or more & 75.2 & 39.0 & 1 \\
\hline \multicolumn{4}{|c|}{ Number of drugs used in the last two weeks* } \\
\hline None & 8.4 & 77.9 & $13.660^{*}$ \\
\hline One & 18.3 & 65.7 & $7.400^{*}$ \\
\hline Two & 22.6 & 47.1 & $3.440^{*}$ \\
\hline Three or more & 50.7 & 20.5 & 1 \\
\hline
\end{tabular}

$n=7,835 ;{ }^{*} p<0.05$; values without asterisk are not significant $(p \geq 0.05)$
Table 4. Multivariate logistic regression SRH for the population aged 65 years or more controlling for region of residence.

\begin{tabular}{|c|c|c|}
\hline Variables & OR & $95 \% \mathrm{Cl}$ \\
\hline \multicolumn{3}{|c|}{ Sociodemographic variables } \\
\hline \multicolumn{3}{|c|}{ Age (83 or more years) } \\
\hline 65 to 82 years & $0.546^{* *}$ & $(0.418,0.713)$ \\
\hline \multicolumn{3}{|c|}{ Monthly family income (More than $1,800 €$ ) } \\
\hline Up to $900 €$ & $0.521^{* *}$ & $(0.362,0.750)$ \\
\hline 901 to $1,200 €$ & $0.607^{*}$ & $(0.409,0.900)$ \\
\hline 1,201 to $1,800 €$ & $0.630^{*}$ & $(0.428,0.927)$ \\
\hline Unknown & 0.700 & $(0.456,1.076)$ \\
\hline \multicolumn{3}{|l|}{ Living alone (No) } \\
\hline Yes & $1.193^{*}$ & $(1.006,1.415)$ \\
\hline
\end{tabular}

Educational attainment (University/2nd cycle secondary and postsecondary)

\begin{tabular}{|l|c|c|}
\hline Illiterate or no education & $0.442^{* *}$ & $(0.328,0.595)$ \\
\hline
\end{tabular}

\begin{tabular}{|l|l|l|}
\hline Primary and secondary 1st cycle & $0.634^{* *}$ & $(0.482,0.833)$ \\
\hline
\end{tabular}

\section{Morbidity and disability}

Chronic disease problem or limitation in the past 12 months (Without disease)

\begin{tabular}{|c|c|c|}
\hline Disease with limitations & $0.176^{* *}$ & $(0.111,0.277)$ \\
\hline Disease without limitations & $0.488^{* *}$ & $(0.321,0.739)$ \\
\hline \multicolumn{3}{|l|}{ Mental health (Good) } \\
\hline Unknown & 0.920 & $(0.592,1.428)$ \\
\hline Not good & $0.484^{* *}$ & $(0.386,0.607)$ \\
\hline
\end{tabular}

Limitation of daily activities in the last 6 months (No)

\begin{tabular}{|l|c|c|}
\hline Yes & $0.472^{\star *}$ & $(0.379,0.587)$ \\
\hline
\end{tabular}

Restriction of normal activities due to pain or symptoms in the last 2 weeks (No)

\begin{tabular}{|l|l|l|}
\hline Yes & $0.721^{*}$ & $(0.538,0.967)$ \\
\hline \multicolumn{3}{|l|}{ You have any functional dependence (No) } \\
\hline Yes & $0.653^{* *}$ & $(0.539,0.793)$ \\
\hline Lifestyle & $1.991^{* *}$ & $(1.505,2.634)$ \\
\hline \multicolumn{3}{|l|}{ Sleep enough hours (No) } \\
\hline Yes & $1.682^{* *}$ & $(1.391,2.034)$ \\
\hline \multicolumn{2}{|l|}{ Physical activity during leisure time (No) } \\
\hline Yes
\end{tabular}

Use of the health services and drug consumption

Time since last medical consultation (1 year or more)

\begin{tabular}{|l|c|c|}
\hline 4 weeks or less & $0.458^{* *}$ & $(0.330,0.636)$ \\
\hline More than 4 weeks and less than 1 year & $0.533^{* *}$ & $(0.383,0.741)$ \\
\hline \multicolumn{2}{|l|}{ Hospitalization in the past 12 months (No) } \\
\hline Yes & $0.701^{* *}$ & $(0.555,0.884)$ \\
\hline
\end{tabular}

Use of the emergency services in the past 12 months (No)

\begin{tabular}{|l|l|l|}
\hline Yes & $0.606^{\star *}$ & $(0.494,0.744)$ \\
\hline
\end{tabular}

Number of drugs used in the last two weeks (Three or more)

\begin{tabular}{|l|c|c|}
\hline None & $4.070^{* *}$ & $(2.881,5.752)$ \\
\hline One & $3.036^{* *}$ & $(2.401,3.840)$ \\
\hline Two & $2.024^{* *}$ & $(1.653,2.479)$ \\
\hline Constant & $11.760^{\star *}$ & $(5.289,26.151)$ \\
\hline
\end{tabular}

$n=7,575 ; F($ Wald $)=25.71 ; p<0.001$

Goodness of fit Hosmer-Lemeshow $=1.425 ; p=0.171 ;{ }^{*} p<0.05 ;{ }^{* *} p<0.01$ 
of the assessment of SRH. These two factors are an indicator of social class, since social class in the NHS is determined by the respondent's last occupation and in this age group is no better measure.

Several similar studies have been conducted in the elderly population using different health questionnaires $(3,4,6,10,23$, 24). Our results are, in broad terms, consistent with those of others except for two factors: age and living alone.

Age does not worsen SRH in the older population. Surprisingly, in this article we have found that among 65 or more year-olds, those aged 83 and older are more likely to report better SRH. These results are not in line with other studies where age is found either to not affect SRH or to worsen it after 65 years of age (4, $6,7,9,24)$. However, these results are similar to another study (11), where in the age group of 50 years or more, persons over 82 years report a better SRH than people between 50 and 82 . There are also researches that explain this relationship between old ages and good SRH: Leinonen's suggestion that adaptation to worsening health plays very important role in self-evaluation of health of the elderly (25). Explanation has been based on continuity theory which focuses on the role of adaptation to ageing and decrease in aspiration level (also in different dimensions of health) in advanced age. In his study, Leinonen assumed that with increasing age, adaptation would occur and a decline in the objective indicators of health and functional performance would not result in decreasing SRH. Tobiasz-Adamczyk and Brzyski (26) analyze changes in SRH and its determinants during the 12-year interval observation, it should be underlined that in spite of the advanced age, the participants of the study scored their health status relatively high. It has been observed that on-going treatment for chronic diseases and subjective perception of chronic conditions (complaints on these diseases and a lack of professional home care in the surroundings) had significant effect on self-rated health, however these health determinants seemed to lose their key importance later on at the advanced old age. Finally, Hnilica (27) reveals that the relationship between age and subjective well-being is generally U-shaped and reaches the minimum in the persons' middle ages not in their old ages.

In addition, our results show that those persons who live alone report better SRH. Although Spain is one of the European countries with the fewest people living alone and living most with their children, there are no studies testing the condition of living alone in relation to SRH. However, our results are in line with other studies (23), that suggested that in interpreting the associations found it should be taken into account that the linkages between health and living arrangements are very likely to be reciprocal. If persons in age of 83 and older have no mobility limitations and perceive their health as good, then they are able to live alone because they do not need every day help and practical support. Accordingly, it can be expected that old people living alone in the community are a selection of healthier people.

Although the univariate analysis shows that women report poor SRH more often than men, this has not been confirmed by the MLR, but it is quite likely that any differences that might be seen between men and women are influenced by other factors (sociodemographic, disease and disability, lifestyle or use of health services). In Spain the reviewed literature on this subject shows that differences across genders exist but are often influenced by various factors such as lifestyle and age $(2,3,21)$.
The level of education and monthly family incomes are important predictors of the assessment of SRH, in line with other studies $(1,5,10,11,22)$.

In the population under study, the use of health services and drug consumption along with lack of diseases, functional dependence and disability variables are closely related to positive SRH. The direction and intensity of these two groups of variables in the assessment of the SRH is in line with those found in previous studies in Spain (3, $4,6,7,9,24)$ and reflects once again the close connection between SRH and factors of morbidity and health services utilization.

Finally, the lifestyle variables are linked to SRH, which is consistent with previous research. The physical exercise in leisure time is an important predictor of positive SRH. This may be because, as people grow older, they need more exercise, since they have higher risk of disease caused by respiratory, bone, circulatory or cardiovascular problems. From our results, we conclude that people who sleep enough hours have better health, but among these people: $69.9 \%$ have good mental health, $64.9 \%$ doing physical activity in leisure time, and $34.5 \%$ have chronic disease with limitation. Therefore, old people who sleep enough hours are a selection of healthier people between old people. That is, this factor is picking up variables related disease, disability and lifestyle.

This study has limitations in that the data correspond to a cross-sectional study and, therefore, we can not establish causal inference from the associations found with SRH. However, this and other studies are necessary to understand the factors that determine or alter health. Besides, this is important in designing effective policies to improve population health, taking into account the specificities of this age group.

In conclusion, the current study revealed that there are determining factors associated with SRH in the elderly Spanish population. In this age group, health inequalities are related to socio-demographic factors, morbidity and disability, the use of health services and lifestyle. Differences in the determinants of health in this age group arise possibly due to different cultural values and social roles assumed by individuals at this stage of life and increased life expectancy in this population. Therefore, it is essential to develop specific interventions for elderly population and from different areas to combat health problems. In contrast to other countries the Spanish Long-Term-Care system is still being developed (28). In 2006, Spain established a Dependency Law (LAPAD) that is implemented in different way by region (29). The Spanish Dependency Law provides a public policy framework at caring for older people in their own homes or in residential care services. The results of our study provide evidence that first option can be more desirable to improve perceived-health in the elderly. Also, in the application of the law it should be taken into account that any health care programme for the elderly must be integral: health care, exercise and social activities.

\section{Conflict of interests}

None declared

\section{REFERENCES}

1. Álvarez C, Peró S. Public health given the challenges of a new century. Report SESPAS 2000 [Internet]. Escuela Andaluza de Salud Pública y Sociedad Española de Salud Pública y Administración Sanitaria, Spain, 2000 [cited 2012 Jul 17]. Available from: http://www.sespas.es/ind_lib04. html. (In Spanish.) 
2. Borrell C, Garcia-Calvente MM, Marti-Bosca JV. Public health from the perspective of gender and social class. Report SESPAS 2004. Gac Sanit. 2004;18(Suppl 1). (In Spanish.)

3. Séculi E, Fusté J, Brugulat $P$, Juncà $S$, Rué $M$, Guillén M. Health selfperception in men and women among the elderly. Gac Sanit. 2001 MayJun;15(3):217-23. (In Spanish.)

4. Gonzalo E, Pasarín MI. Health among the elderly. Gac Sanit. 2004 May;18 Suppl 1:69-80. (In Spanish).

5. Social inequalities in health, lifestyles and use of health services in autonomous communities, 1993-2003 [Internet]. Agencia de Salud Pública de Barcelona; 2006 [cited 2012 Jul 17]. Available from: http://www.msc. es/organizacion/sns/planCalidadSNS/pdf/equidad/Desigualdades_sociales_salud_y_SS.pdf. (In Spanish.)

6. Hidalgo A, del Llano J, Pérez S. The Spanish in front of the health and its determinants. (Refer 095) [Internet]. Edit Forum Sanofi-Aventis, Spain, 2007 [cited 2012 Jul 17]. Available from: http://www.fgcasal.org/fgcasal/ PUBLICACIONES.asp?buscar=\&paginaactual=31. (In Spanish.)

7. AETS (Spanish Health Technology Assessment Agency). Analysis of the 1977 Spanish National Health Survey. IPE-01/29 (Public report). Report of health technology assessment, No 29. Madrid: Instituto de Salud Carlos III; 2001.

8. Pérula de Torres LA, Martínez de la Iglesia J, Ruiz Moral R, Fonseca del Pozo J. Variables related to the self-perceived health status: a population study. Aten Primaria. 1995 Oct 15;16(6):323-9. (In Spanish.)

9. Azpiazu Garrido M, Cruz Jentoft A, Villagrasa Ferrer JR, Abanades Herranz JC, García Marín N, Valero de Bernabé FA. Factors related to perceived poor health condition or poor quality of life among those over 65 years of age. Rev Esp Salud Publica. 2002 Nov-Dec;76(6):683-99. (In Spanish.)

10. Prieto-Flores ME, Fernández-Mayoralas G, Rojo-Pérez F, Lardiés-Bosque $\mathrm{R}$, Rodríguez-Rodríguez V, Ahmed-Mohamed K, et al. Sociodemographic and health factors explaining emotional wellbeing as a quality of life domain of older people in Madrid, Spain. 2005. Rev Esp Salud Publica. 2008 May-Jun;82(3):301-13. (In Spanish.)

11. Girón P. Determinants of self-rated health in Spain: differences by age groups for adults. Eur J Public Health. 2012 Feb;22(1):36-40.

12. Robine JM, Jagger C, Egidi V, editors. Selection of a coherent set of health indicators. Final draft: a first step towards a user's guide to health expectancies for the European Union. Montpellier (France): Euro-REVES; 2000.

13. National Statistics Institute (INE). National Health Survey 2006. Methodology detailed [Internet]. [cited 2012 Jul 17]. Available from: http:// www.ine.es/metodologia/t15/t153041906.pdf. (In Spanish.)

14. Ministry of Health. National Health Survey Spain 2006. Adult questionnaire and household questionnaire [Internet]. [cited 2012 Jul 17]. Available from: http://www.msps.es/estadEstudios/estadisticas/encuestaNacional/encuesta2006.htm. (In Spanish.)
15. Domingo-Salvany A, Regidor E, Alonso J, Alvarez-Dardet C; Working Group of the Spanish Society of Epidemiology and the Spanish Society of Family and Community Medicine. Proposal for a social class measure. Aten Primaria. 2000 Mar 31;25(5):350-63. (In Spanish.)

16. Cañizares Pérez M, Barroso Utra I, Alfonso León A, García Roche R, Alfonso Sagué K, Chang de la Rosa M, et al. Estimate methods used with complex sampling designs: their application in the Cuban 2001 health survey. Rev Panam Salud Publica. 2004 Mar;15(3):176-84. (In Spanish.)

17. Vittinghoff E, Glidden DV, Shiboski SC, McCulloch CE. Regression methods in biostatistics: linear, logistic, survival, and repeated measures models. New York: Springer; 2005.

18. Maldonado G, Greenland S. Simulation study of confounder-selection strategies. Am J Epidemiol. 1993 Dec 1;138(11):923-36.

19. Bursac Z, Gauss CH, Williams DK, Hosmer DW. Purposeful selection of variables in logistic regression. Source Code Biol Med. 2008 Dec $16 ; 3: 17$

20. Archer J, Lemeshow S. Goodness-of-fit test for a logistic regression model fitted using survey sample data. Stata J. 2006;6(1):97-105.

21. Borrell C, Artazcoz L. Inequalities gender on health: challenges for the future. Rev Esp Salud Publica. 2008 May-Jun;82(3):245-9. (In Spanish.)

22. Wilkinson R, Marmot M, editors. Social determinants of health: the solid facts. 2nd ed. Copenhagen: WHO Reginal Office for Europe; 2003.

23. Rueda S, Artazcoz L, Navarro V. Health inequalities among the elderly in western Europe. J Epidemiol Community Health. 2008 Jun;62(6):492-8.

24. Fernández-Mayoralas G, Rojo Pérez F, Prieto Flores ME, et al. The meaning of health in quality of life on the elderly. Older portal report 2007; 74 [Internet]. [cited 2012 Jul 17]. Available from: http://www. imsersomayores.csic.es/documentacion/estudiosyresultados/informes/ index.html. (In Spanish.)

25. Leinonen R, Heikkinen E, Jylhä M. Predictors of decline in self-assessments of health among older people - a 5-year longitudinal study. Soc Sci Med. 2001 May;52(9):1329-41.

26. Tobiasz-Adamczyk B, Brzyski P. Factors determining changes in selfrated health in the Polish community-dwelling elderly. Cent Eur J Public Health. 2005 Sep;13(3):117-24.

27. Hnilica K. Discrimination and subjective well-being: protective influences of membership in a discriminated category. Cent Eur J Public Health. 2011 Mar;19(1):3-6.

28. Ležovič M, Raučinová M, Kováč A, Moricová S, Kováč R. Long-term care in developed countries and recommendations for Slovak Republic. Cent Eur J Public Health. 2008 Mar;16(1):21-5.

29. Gútierrez MF, Jiménez-Martín S, Vegas Sánchez R, Villaplana C. The Spanish long-term care system: ENEPRI research report, no. 88 [Internet]. ENEPRI; 2010 [cited 2012 Jul 17]. Available from: http://aei.pitt. edu/14603/1/Spain.pdf.

Received April 26, 2011

Accepted in revised form June 4, 2012 